\title{
Yritysaineistoon perustuva maatalouden kokonaislaskenta
}

\author{
Arto Latukka ${ }^{1)} \&$ Maria Yli-Heikkilä ${ }^{2}$ \\ ${ }^{1)}$ MTT Taloustutkimus, Latokartanonkaari 9,00790 Helsinki, arto.latukka@mtt.fi \\ ${ }^{2)}$ MTT Taloustutkimus, Latokartanonkaari 9,00790 Helsinki, maria.yli-heikkila@mtt.fi
}

\section{Tiivistelmä}

MTT Taloustutkimuksessa siirryttiin vuodesta 2011 laskemaan koko Suomen maataloussektorin talouskehitystä kuvaavat kokonaisluvut suoriteperusteiseen kannattavuuskirjanpitoaineistoon perustuen. Tämä maatalouden kokonaislaskenta -järjestelmä ja sen vuosikohtaiset tulokset julkistettiin keväällä 2011 (www.mtt.fi/taloustohtori/kokonaislaskenta). Järjestelmä korvaa MTT:ssä 1950-luvulta asti tuotetun maatalouden kassaperusteisen kokonaislaskelman.

Uudessa järjestelmässä tulokset lasketaan yksittäisten kirjanpitotilojen luvuista painottamalla ja summaamalla. Tilakohtaiset painokertoimet lasketaan numeerisella optimoinnilla vuosittain siten, että tilamäärä ja viljelyalat painokertoimilla kerrottuna ja summattuna vastaavat koko maan tasolla ja tukialueittain vastaavia kokonaistilamääriä ja viljelyaloja. Tukialueiden sisällä tilamäärään perustuva painotus tehdään tilakokoluokittain, jotta tulokset saadaan vastaamaan kunkin alueen todellista tilakokojakaumaa. Kokonaistilamäärät perustuvat Tiken maatalouden rakenneaineistoon, joka on nähtävissä mm. Taloustohtorin rakennekehitys -verkkopalvelussa (www.mtt.fi/taloustohtori/rakennekehitys). Tähän mennessä tulokset on esitetty vain vuosisarjoina vuodesta 2000 lähtien.

Tähän tarkasteluun painokerrointen laskentaa täsmennettiin siten, että painokerrointen summat vastaavat vuosittain täsmällisesti rakenneaineiston kokonaistilamääriä. Samalla tarkastelua kohdennettiin vuosikohtaisten tulosten lisäksi myös tukialueittaisiin tuloksiin. Tukialueittaisessa tarkastelussa pohjoisimmat tukialueet $\mathrm{C} 2 \mathrm{p}, \mathrm{C} 3$ ja $\mathrm{C} 4$ yhdistettiin, koska kirjanpitotiloja on absoluuttisesti noilla alueilla vähän. Tulokset ovat erityisesti tukialue-tarkastelun osalta alustavia, koska alueittaiset tulokset tuottava painotusjärjestelmä on vielä kehitystyön kohteena.

Koko toimialaa koskeville alueellisille tarkasteluille tuo merkittävää lisäarvoa se, että laskenta pohjautuu nyt yritystason kannattavuuskirjanpitotiloilta kerättäviin tietoihin, jolloin myös yrittäjäperheen omista resursseista eli työstä ja pääomasta aiheutuvat kustannussummat voidaan ottaa huomioon. Tarkastelu osoittaakin, että yrittäjäperheen omille resursseille korvaukseksi jäävät yrittäjätulosummat, absoluuttisena tai tilaa kohti laskettuna, kertovat vain osatotuuden eri alueiden taloustilanteesta. Kun työmäärä ja myös tuotantoon tarvittu oma pääoma otetaan huomioon, eri alueiden vertailuissa taloustilanne voi kääntyä jopa päinvastaiseksi.

Alustavatkin tulokset osoittavat, että tukialuekohtaisille kannattavuus- ja vakavaraisuustuloksille on tarvetta. Jatkossa tavoitteena on tuottaa myös rahavirtalaskelmat, joilla on mielenkiintoa myös erityisesti aluetalouden näkökulmasta. Aluetarkastelumahdollisuuden laajentamiseksi painotusjärjestelmää on kehitetty myös siihen suuntaan, että jatkossa kyettäisiin tuottamaan tulokset myös NUTS2- ja FADN -aluejaolla.

Asiasanat: Taloustohtori, maatalous, kokonaislaskenta, kokonaislaskelma, kannattavuuskirjanpito 


\section{Johdanto}

MTT:n maatalouden kannattavuuskirjanpidossa lasketaan vuosittain Suomen maatalous- ja puutarhayritysten kannattavuustulokset, jotka painotettuna kuvaavat Suomen 38000 suurimman yrityksen keskiarvotuloksia. Myös näiden ulkopuolelle jääneiden kirjanpitoaineiston pienimpien tilojen tuloksia hyödynnetään nykyään siten, että näiden perusteella lasketaan pienimpien noin 25000 tilan painotetut tulokset. Keskiarvojen asemesta laskennassa tarkastellaan kaikkien näiden tilojen summana saatavaa koko Suomen maa- ja puutarhataloutta kuvaavia kokonaistuloksia. Tämä maatalouden kokonaislaskenta -järjestelmä ja sen tulokset julkistettiin keväällä 2011 (www.mtt.fi/taloustohtori/kokonaislaskenta). Järjestelmä korvaa MTT:ssä 1950-luvulta asti tuotetun maatalouden kassaperusteisen kokonaislaskelman. .

Koska laskenta pohjautuu nyt yritystasolta kannattavuuskirjanpitotiloilta kerättäviin tietoihin, voidaan tuloksia tarkastella vuosikohtaisten sarjojen lisäksi myös alueittain ja tuotantosuunnittain ja tarkasteluun saadaan myös paitsi tuloksiin niin myös kannattavuuteen, vakavaraisuuteen, maksuvalmiuteen jne. liittyvät tulokset.

\section{Aineisto ja menetelmät}

Maatalouden kokonaislaskennassa tulokset lasketaan painottamalla ja summaamalla MTT:n maa- ja puutarhatalouden yrityskohtaisen kannattavuuskirjanpitotila-aineiston luvut halutulle kokonaistasolle (koko maa tai tukialue). Tilakohtaiset painokertoimet lasketaan numeerisella optimoinnilla vuosittain siten, että tilamäärä ja viljelyalat painokertoimilla kerrottuna ja summattuna vastaavat koko maan tasolla ja tukialueittain vastaavia kokonaistilamääriä ja viljelyaloja. Tukialueiden sisällä tilamäärään perustuva painotus tehdään tilakokoluokittain, jotta tulokset saadaan vastaamaan todellista tilakokojakaumaa. Painotus perustuu tilamäärien osalta Tiken maatalouden rakenneaineiston tukialueittaisiin ja tilakokoluokittaisiin kokonaistilamääriin (ks. esim. MTT:n Taloustohtori -sivuston Rakennekehitysverkkopalvelu: mtt.fi/taloustohtori/rakennekehitys). Painokerrointen määrittelyssä ei käytetä yritysten talousmuuttujia, koska niitä ei ole kovin luotettavasti saatavissa koko maan tasolta.

Painotuksessa kirjapitotila-aineistolle lasketaan painovektori, josta saadaan kullekin tilalle painokertoimet. Painovektori saadaan minimoimalla tavoitepainot. Tässä käytetään epälineaarista optimointia, jossa tavoitefunktio on kvadraattinen ja rajoitefunktiot lineaarisia:

$$
\begin{aligned}
& \arg \min _{\mathbf{x}} \quad \mathbf{x}^{T} \mathbf{x} \\
& \text { s.t. } \\
& \mathrm{x}^{T} \mathrm{a}= \\
& \sum_{i} \mathrm{x}_{i}^{T}=b_{i}, \quad i=1, \ldots, 11, \\
& \mathrm{x}_{n} \geq 1, \quad n=1, \ldots, 965, \\
& \mathrm{x}, \mathrm{a} \in \mathbb{R}^{n} \text {. }
\end{aligned}
$$

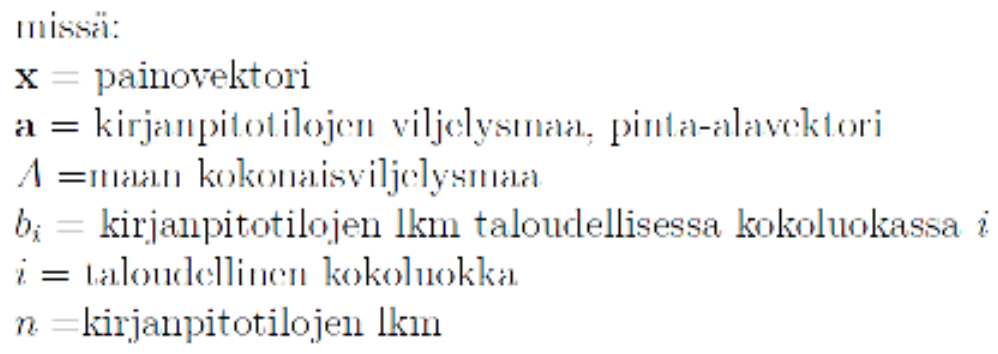

Painolaskennassa käytetyt parametrit ovat viljelysmaa-ala, taloudellinen tilakoko ja alueluokitteluna tukialue. Tavoite on rajoitteet huomioiden minimoida painokertoimet, jolloin yksittäisten mahdollisten poikkeavien tilojenkin painokertoimet pysyisivät mahdollisimman alhaisina. Minkään tilan painokerroin ei voi kuitenkaan olla alle ykkösen (3. rajoite). Optimointi-tehtävä sinänsä lasketaan tukialueittain, mutta kuitenkin siten, että pohjoisimpien tukialueiden $\mathrm{C} 2 \mathrm{p}, \mathrm{C} 3$ ja C4 painot optimoidaan yhdellä 
kertaa. Painotetun viljelysalan on vastattava tukialueen viljelysalaa (1. rajoite). Lisäksi painotettu tilojen lukumäärä on vastattava tilakokoryhmittäin vastaavaa todellista tilalukumäärää (2. rajoite). Optimoinnissa 11 taloudellista kokoluokkaa on yhdistetty neljäksi tilakokoryhmäksi: 1-3, 4-6, 7-9 ja 1011. Pohjoisilla tukialueilla $(\mathrm{C} 2 \mathrm{p}, \mathrm{C} 3$ ja $\mathrm{C} 4)$ ryhmät $1-3$ ja 4-6 on pienemmän tilamäärän vuoksi yhdistetty.

Optimointitehtävä on ratkaistu Matlabin fmincon -funktiolla, joka perustuu toistetun kvadraattisen optimoinnin menetelmään (SQP). Kuviossa 1 on esitetty painojen suuruus tilakokoluokittain. Pienimpien kannattavuuskirjanpitotilojen painokertoimet ovat keskimäärin suurempia ja muutamilla kaikkein pienimmistä tiloista hyvinkin suuria verrattuna tilakooltaan suurempien kannattavuuskirjanpitotilojen painokertoimiin. Tämä johtuu siitä, että kannattavuuskirjanpidossa aivan pienimpien tilojen lukumäärä on vähäinen verrattuna niiden määrään koko maan tasolla. Suuret painokertoimet eivät kuitenkaan heikennä tulosten luotettavuutta, koska absoluuttisesti näiden aivan pienimpien tilojen talousluvut ovat kuitenkin pieniä.

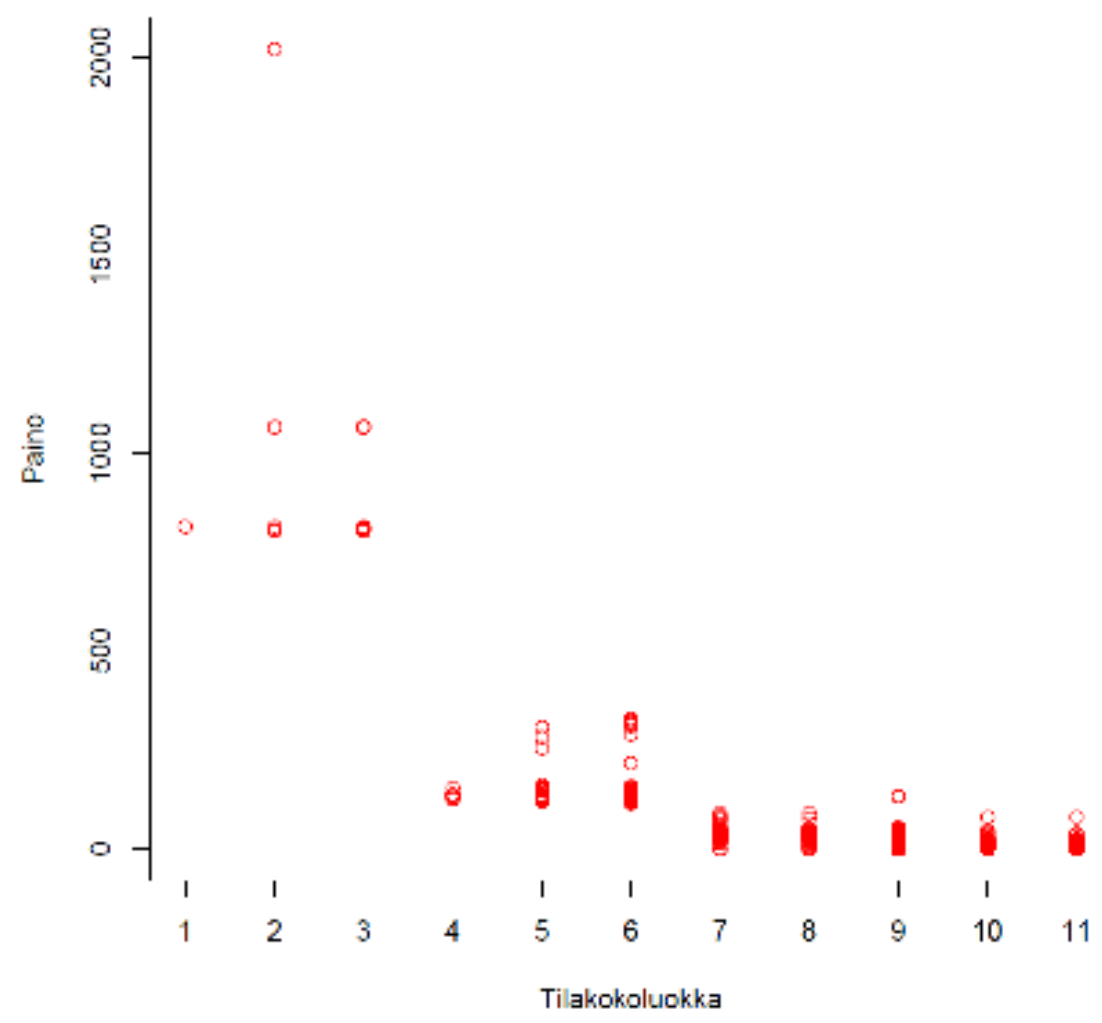

Kuvio 1. Kannattavuuskirjanpitotilojen painokertoimien suuruus tilakokoluokittain.

Kokonaislaskennassa käytettävä painotus poikkeaa kannattavuuskirjanpidon keskiarvotuloksia laskettaessa käytettävästä EU:n käyttämään alueittaisiin, tuotantosuunnittaisiin ja tilakokoluokittaisiin kokonaistilamääriin perustuvaan painokerrointen laskentaan. Siinä kunkin kirjanpitotilan painokerroin muodostuu siitä, että kuinka suurta tilamäärää tila edustaa omassa tuotantosuunnassaan ja tilakokoluokassaan alueellaan.

Maatalouden kokonaislaskennassa tuotetut ennusteet perustuvat kullekin kirjanpitotilalle tehtyihin ennusteisiin. Yrityskohtaisissa ennusteissa huomioidaan edeltävän vuoden panos- ja tuottajahintakehitys tuote- ja kustannuserittäin, tukimuutokset tukilajeittain sekä alueittaiset keskisatomuutokset kasveittain. Tilojen tuotantorakenne ja tilakoko pysyvät samoina. Vaikka näitä ennustemallissa ei sinänsä kyetä ennustamaan, kokonaislaskennan ennustetuloksissa rakennekehitys tulee huomioitua siten, että ennustevuoden painolaskenta perustuu tilarakenteesta tehtyyn ennusteeseen. Tuotannosta luopuvat ovat pääosin pienempiä yrityksiä, jolloin suurempien kirjanpitotilojen painokertoimet kasvavat ja niiden vaikutus kasvaa.

Maatalouden Kokonaislaskenta - palvelussa on myös tunnusluku-raportti, jossa luvut esitetään vuoden 2010 hintatasoon deflatoituna. Deflatointi perustuu Eurostatin Yhdenmukaistettuun Kuluttaja- 
hintaindeksiin, YKHI (engl. HICP, Harmonized Indices of Consumer Prices). Tähän päädyttiin kansallisten indeksien asemesta, koska jatkossa deflatoidut tulokset tuotetaan kaikista EU-jäsenmaista ja haluttiin välttää kahdet deflatoidut tulokset Suomen osalta.

\section{Tulokset}

Maatalouden kokonaislaskennan vuosittaiset tunnusluvut 2000-luvulta on esitetty taulukossa 1. Vuoden 2010 tulokset ovat ennakollisia ja muidenkin vuosien tulokset ovat alustavia, koska tämän 2011 julkistetun järjestelmän painotus- ja laskentamenetelmiä kehitetään jatkuvasti. Taulukon ensimmäiseltä riviltä näkyy, millaista tilamäärää kirjanpitotilojen tulokset on painotettu vuosittain edustamaan. Kunkin vuoden kirjanpitotilojen määrä näkyy toiselta riviltä.

Taulukko 1. MTT:n Maatalouden Kokonaislaskennan tunnusluvut vuosittain (lähde: Taloustohtorin Maatalouden kokonaislaskenta -palvelu. mtt.fi/kokonaislaskenta)

\begin{tabular}{|c|c|c|c|c|c|c|c|c|c|c|c|}
\hline Tunnusluvut & 2010 e. $43 \%$ valmiita & 2009 & 2008 & 2007 & 2006 & 2005 & 2004 & 2003 & 2002 & 2001 & 2000 \\
\hline Tiloja edustettuna & 63.854 & 65.314 & 67.023 & 68.227 & 70.493 & 70.602 & 73.047 & 74.964 & 76.287 & 78.36 & 81.183 \\
\hline Tiloja otoksessa & 964 & 959 & 968 & 977 & 952 & 947 & 903 & 873 & 867 & 894 & 929 \\
\hline тUотот, milj.euroa & 5.983 & 5.826 & 6.232 & 6.043 & 5.372 & 5.282 & 5.43 & 5.233 & 5.378 & 5.137 & 5.183 \\
\hline $\begin{array}{r}\text { TUOTANTOKUSTANNUS, } \\
\text { milj.euroa }\end{array}$ & 7.317 & 7.395 & 7.597 & 7.097 & 6.744 & 6.653 & 6.808 & 6.558 & 6.536 & 5.917 & 5.886 \\
\hline Yrittäjänvoitto, milj.euroa & -1.332 & -1.566 & -1.36 & -1.05 & -1.369 & -1.364 & -1.373 & -1.322 & -1.155 & -777 & -700 \\
\hline Yrittäjätulo, milj.euroa & 933 & 574 & 796 & 1.13 & 822 & 945 & 920 & 926 & 1.129 & 1.05 & 1.185 \\
\hline Kannattavuuskerroin & 0,41 & 0,27 & 0,37 & 0,52 & 0,38 & 0,41 & 0,40 & 0,41 & 0,49 & 0,57 & 0,63 \\
\hline Työansio, milj.euroa' & $178^{\prime}$ & $-39^{\prime}$ & $196^{\prime}$ & $554^{\prime}$ & $271^{\prime}$ & $416^{\prime}$ & $395^{\prime}$ & $427^{\prime}$ & $629^{\prime}$ & $565^{\prime}$ & 689 \\
\hline Työtuntiansio & 1,7 & $-0,3$ & 1,6 & 4,4 & 2,0 & 2,9 & 2,6 & 2,8 & 3,8 & 3,3 & 3,8 \\
\hline Omavaraisuusaste & $72^{\prime}$ & $72^{\prime}$ & $72^{\prime}$ & $73^{\prime}$ & $74^{\prime}$ & $75^{\prime}$ & $75^{\prime}$ & $75^{\prime}$ & $77^{\prime}$ & $76^{\prime}$ & 77 \\
\hline Kokonaispääoman tuotto-\% & $-2,7$ & $-4,8$ & $-3,3$ & $-1,9$ & $-4,5$ & $-5,1$ & $-5,2$ & $-5,3$ & $-4,0$ & $-1,1$ & $-0,5$ \\
\hline
\end{tabular}

Yrittäjätulo on vaihdellut voimakkaasti vuosittain ja se ei ole riittänyt kattamaan yhtenäkään vuonna omasta työstä ja omasta pääomasta vuosittain aiheutuneita kustannuksia, mikä näkyy yrittäjävoiton negatiivisuudesta. Vastaavasti kokonaispääoman tuotto-\% on ollut joka vuosi negatiivinen. Maatalouden kokonaislaskenta -palvelusta on nähtävissä tulosanalysointia varten myös $\mathrm{mm}$. tuotto- ja kustannuserittelyt. Koska tuloksissa on edustettuna myös kaikkein pienimmät yritykset, kannattavuuskerroin on tässä alhaisempi kuin noin 38.000 suurimman yrityksen keskiarvotuloksia kuvaavissa kannattavuuskirjanpitotuloksissa. Taulukon 1 tulokset paljastavat myös sen, että maatalouden velkaantuminen on lisääntynyt, koska keskimääräinen omavaraisuusaste eli oman pääoman osuus koko pääomasta on laskenut 77 prosentista 72 prosenttiin.

Taulukko 2. MTT:n Maatalouden Kokonaislaskennan vuoden 2009 tunnusluvut tukialueittain

\begin{tabular}{|c|c|c|c|c|c|c|}
\hline \multirow{2}{*}{ Tunnusluvut } & \multicolumn{6}{|c|}{$\begin{array}{r}2009 \\
\end{array}$} \\
\hline & C2p_alue *C3_alue *C4_alue & C2_alue & C1_alue & B_alue & A_alue & Keskiarvo \\
\hline Tiloja edustettuna & 5.353 & 17.078 & 15.263 & 19.362 & 8.258 & 65.314 \\
\hline Tiloja otoksessa & 91 & 285 & 218 & 233 & 132 & 959 \\
\hline TUотот, milj.euroa & 580 & 1.583 & 1.35 & 1.556 & 758 & 5.826 \\
\hline $\begin{array}{r}\text { TUOTANTOKUSTANNUS, } \\
\text { milj.euroa }\end{array}$ & 731 & 1.939 & 1.705 & 2.042 & 979 & 7.395 \\
\hline Yrittäjänvoitto, milj.euroa & -151 & -355 & -354 & -485 & -221 & -1.566 \\
\hline Yrittäjätulo, milj.euroa & 78 & 238 & 112 & 103 & 44 & 574 \\
\hline Kannattavuuskerroin & 0,34 & 0,40 & 0,24 & 0,17 & 0,17 & 0.27 \\
\hline Työansio, milj.euroa ' & $45^{\prime}$ & 85 & -18 & -90 & $-61^{\prime}$ & -39 \\
\hline Työtuntiansio & 3,1 & 2,6 & $-0,7$ & $-3,1$ & $-4,8$ & $-0,3$ \\
\hline Omavaraisuusaste ' & 68 & 70 & 69 & 73 & $78^{\prime}$ & 72 \\
\hline Kokonaispääoman tuotto-\% & $-11,6$ & $-3,7$ & $-5,1$ & $-4,8$ & $-3,6$ & $-4,8$ \\
\hline Palkkavaatimus & 196 & 440 & 336 & 395 & 159 & 1.527 \\
\hline Korkovaatimus & 32 & 152 & 130 & 193 & 105 & 613 \\
\hline
\end{tabular}

Taulukossa 2 on esitetty tilivuoden 2009 tulokset tukialueittain siten, että pohjoisimpien tukialueiden tulokset on summattu tilamäärän alhaisuuden vuoksi. Tässä aluetulosten summaamisessa on käytetty Taloustohtorin verkkopalveluihin tulevaa uutta ominaisuutta. 
Taulukossa on aluekohtaiset kokonaissummat, mutta tilakohtaisen analyysin tekemiseksi tulokset tulee jakaa "tiloja edustettuna" -sarakkeen tilamäärillä. Näin nähdään esimerkiksi että, Btukialueen A-tukialueeseen verrattuna suuremmasta yrittäjätulosummasta huolimatta yrittäjätulo tilaa kohti on näillä kutakuinkin sama, noin 5.300 euroa. Kun vastaavasti A- ja B-tukialueilla viljelijäperheiden tekemästä työstä ja yritystoimintaan sijoittamasta omasta pääomasta aiheutuva kustannussumma on myös kutakuinkin sama, kannattavuuskerroin on alueilla sama. Pelkän yrittäjätulosumman (maataloustulosumman) vertailu eri alueiden välillä ei näin paljasta mitään alueiden kannattavuustilanteesta.

Vertailun vuoksi Taulukkoon 3. on haettu tilivuoden 2007 tunnusluvut, josta näkyy selkeästi, että "vuodet eivät ole veljeksiä". Tilivuonna 2007 tukialueella A kannattavuus oli Suomen paras, kun se vuonna 2009 oli laskenut B-alueen kanssa heikoimmaksi Suomessa.

Taulukko 3. MTT:n Maatalouden Kokonaislaskennan vuoden 2007 tunnusluvut tukialueittain (lähde: Taloustohtorin Maatalouden kokonaislaskenta -palvelu. mtt.fi/kokonaislaskenta)

\begin{tabular}{|c|c|c|c|c|c|c|}
\hline \multirow[t]{2}{*}{ Tunnusluvut } & \multicolumn{6}{|c|}{2007} \\
\hline & C2p_alue *C3_alue *C4_alue & C2_alue & C1_alue & B_alue & A_alue & Keskiaruo \\
\hline Tiloja edustettuna & 4.54 & 16.851 & 20.575 & 19.596 & 6.665 & 68.227 \\
\hline Tiloja otoksessa & 89 & 283 & 223 & 258 & 124 & 977 \\
\hline тUотот, milj.euroa & 545 & 1.594 & 1.529 & 1.722 & 652 & 6.043 \\
\hline $\begin{array}{r}\text { TUOTANTOKUSTANNUS , } \\
\text { milj.euroa }\end{array}$ & 650 & 1.941 & 1.752 & 2.02 & 734 & 7.097 \\
\hline Yrittäjänvoitto, milj.euroa & -105 & -345 & -223 & -295 & -81 & -1.05 \\
\hline Yrittäjätulo , milj.euroa & 102 & 296 & 306 & 286 & 140 & 1.13 \\
\hline Kannattavuuskerroin & 0,49 & 0,46 & 0,58 & 0,49 & 0,63 & 0,52 \\
\hline Työansio, milj.euroa' & $66^{\prime}$ & $150^{\prime}$ & $162^{\prime}$ & 111 & $66^{\circ}$ & 554 \\
\hline Työtuntiansio & 4,9 & 3,8 & 5,3 & 3,4 & 5,6 & 4,4 \\
\hline Omavaraisuusaste & $66^{\prime}$ & $71^{\prime}$ & $73^{\circ}$ & $75^{\prime}$ & $79^{\circ}$ & 73 \\
\hline Kokonaispääoman tuotto-\% & $-4,9$ & $-3,5$ & $-0,9$ & $-1,5$ & 0,5 & $-1,9$ \\
\hline Palkkavaatimus & 171 & 495 & 385 & 406 & 147 & 1.604 \\
\hline Korkovaatimus & 36 & 146 & 145 & 175 & 74 & 575 \\
\hline
\end{tabular}

\section{Johtopäätökset}

Tämän artikkelin kirjoitushetkellä Taloustohtori -sivustolla maatalouden kokonaislaskenta -palvelussa on tarjolla vain vuosikohtaiset tulokset. Niihin nähden tässä tarkastelussa painojen laskentaa on täsmennetty ja tulokset on tuotettu alustavasti myös tukialueittain.

Painotuksen kohteena oleva kirjanpitotilojen joukko ei pysty täydellisesti kuvaamaan koko Suomen maatalousyritysten moninaista joukkoa. Maatalouden kokonaislaskennalla koko sektorista saadaan kuitenkin ehyt ja monipuolinen kokonaiskuva ja alustavien tulosten mukaan myös luotettavien aluetason tuloksien tarjonta tulee mahdolliseksi.

Alustavatkin tulokset osoittavat, että tukialuekohtaisille tuloksille on tarvetta. Kannattavuuskirjanpidossa yrittäjän omista työ- ja pääomaresursseista aiheutuvien kustannusten huomiointi ja käyvät tasearvot mahdollistavat tulostarkastelun lisäksi myös kannattavuuden ja vakavaraisuuden tarkastelun, mikä tuo merkittävää lisäarvoa koko toimialaa koskeville aluetason tarkasteluille. Jatkossa tuotetaan myös rahavirtalaskelmat, joilla on mielenkiintoa myös erityisesti aluetalouden näkökulmasta. Tämän myötä painotusjärjestelmää on kehitetty myös siihen suuntaan, että jatkossa kyettäisiin tuottamaan tulokset myös mm. NUTS2- ja FADN -aluejaolla.

\section{Kirjallisuus}

Latukka, A. \& Järvinen, J. 2011. Maatalouden kokonaistason laskenta uudistuu. Teoksessa Niemi, J. \& Ahlstedt, J. (toim.). 2011. Suomen maatalous ja maaseutuelinkeinot 2011. Maa- ja elintarviketalouden tutkimuskeskus. Taloustutkimus. Julkaisuja 111.2 s.

Yli-Heikkilä, M. 2011. Total calculation based on weighted farm level accounting data. Seminaari-julkaisu ja alustus. 19th PACIOLI -workshop.

MTT Taloustohtori -sivusto: Maatalouden kokonaislaskenta -verkkopalvelu. www.mtt.fi/taloustohtori/kokonaislaskenta 